\title{
Central Giant Cell Granuloma in a Child - Case Report
}

\author{
Granuloma Central de Células Gigantes en un Niño - Reporte de un Caso
}

\author{
Soukayna Bahbah"; Saloua Dghoughi"; Hakima Chhoull" \& Wafaa El Wady ${ }^{*+*+*}$
}

BAHBAH, S.; DGHOUGHI, S.; CHHOUL, H.; EL WADY, W. Central Giant cell granuloma in a child - Case report. Int. J. Odontostomat., 10(3):393-397, 2016.

ABSTRACT: This article describes a case of central giant cell granuloma in the right posterior region of the mandible in a 10- year-old boy. The lesion was removed by curettage and a histopathological examination was carried out.

KEY WORDS: central giant cell granuloma, child, mandible.

\section{INTRODUCTION}

Central giant cell granuloma (CGCG) is a nonneoplasic lesion of unknown etiology. This lesion was initially described by Jaffe in 1953 as a "reparative" reaction, but this term was abandoned when it was proven to be more destructive than reparative in nature (Auclair et al., 1988; Bataineh et al., 2002; De Lange \& Van den Akker, 2005). The World Health Organization has defined it as an intraosseous lesion consisting of cellular fibrous tissue that contains multiple foci of hemorrhage, aggregations of multinucleated giant cells and occasionally trabeculae of woven bone (Kaffe et al., 1996).

CGCG accounts for less than $7 \%$ of all benign lesions of jaws. There is predilection in patients younger than 30 years and it occurs more frequently in females, in the anterior region of mandible (Bataineh et al.; Marx \& Stern, 2003).

Giant cell lesions of jaws demonstrate variable clinical behavior and radiological changes. The lesions varies from a slow growing painless swelling to a rapidly aggressive lesion that presents with pain, cortical perforation, root displacement or root resorption (Liu et al., 2003).

Radiographic findings are diverse, ranging from small apical lesions to large multilocular lesions, with varying degrees of expansion (Marx \& Stern). This radiographic appearance is not pathognomonic and may be confused with several other lesions of jaws (Bataineh et al.; Liu et al.; Marx \& Stern, 2003).

Diagnosis of CGCG is based on histopathology, characterized by presence of numerous multinucleated giant cells in a prominent fibrous stroma (Bataineh et al.; Liu et al.; Mooney et al., 2007).

The reported case is about a 10-year-old patient, with a mandibular central giant cell granuloma treated by curettage.

\section{CASE REPORT}

A 10 year old boy presented to the department of Oral surgery with his mother for a painless progressive swelling on the left posterior mandible. The patient's medical history was unremarkable.

The extraoral examination did not reveal abnormalities. Intraoral examination showed a firm sessile and depressible bluish mass on the left mandibular premolar area. According to his mother, the

\footnotetext{
Resident Dentist, Department of Oral Surgery-Consultation Center of Dental Treatment (CCDT), Faculty of Dentistry, University Mohamed V Suissi, Rabat, Morocco.

* Professor assistant, Department of Oral Surgery-Consultation Center of Dental Treatment (CCDT), Faculty of Dentistry, University Mohamed V Suissi, Rabat, Morocco.

** Professor, Department of Pediatric Dentistry-Consultation Center of Dental Treatment, Faculty of Dentistry, University Mohamed V Suissi, Rabat, Morocco.

${ }_{* * *}$ Professor and Chief Service of Oral Surgery-Consultation Center of Dental Treatment, Faculty of Dentistry, University Mohamed V Suissi, Rabat, Morocco.
} 
lesion appears three months ago after left temporary first and second premolars removal by a dental practitioner. Thinking of an infectious cause, he prescribed an antibiotic and an anti-inflammatory which did not help the lesion to regress. That is what brought them to seek medical care.

The mass caused buccal and lingual expansion and extended from the first permanent molar to the first premolar which seemed immersed in the lesion. The top of the lesion showed the antagonistic teeth print (Fig. 1).

Neck palpation was negative. There were no signs or symptoms of infection. No history of trauma was reported. Vitality tests proved positive on the first lower molar and premolar. No mobility was noted.

The panoramic radiograph showed a welldefined radiolucency extending from the first permanent molar to the first premolar, in relation to the apices of teeth. The second premolar was on eruption process. Root shape was not achieved, and no root resorption was observed (Fig. 2).

Laboratory investigations included serum calcium, phosphorus, alkaline phosphate and parathormon (PTH). All the reports were within normal limits, excluding brown tumor of hyperparathyroidism.

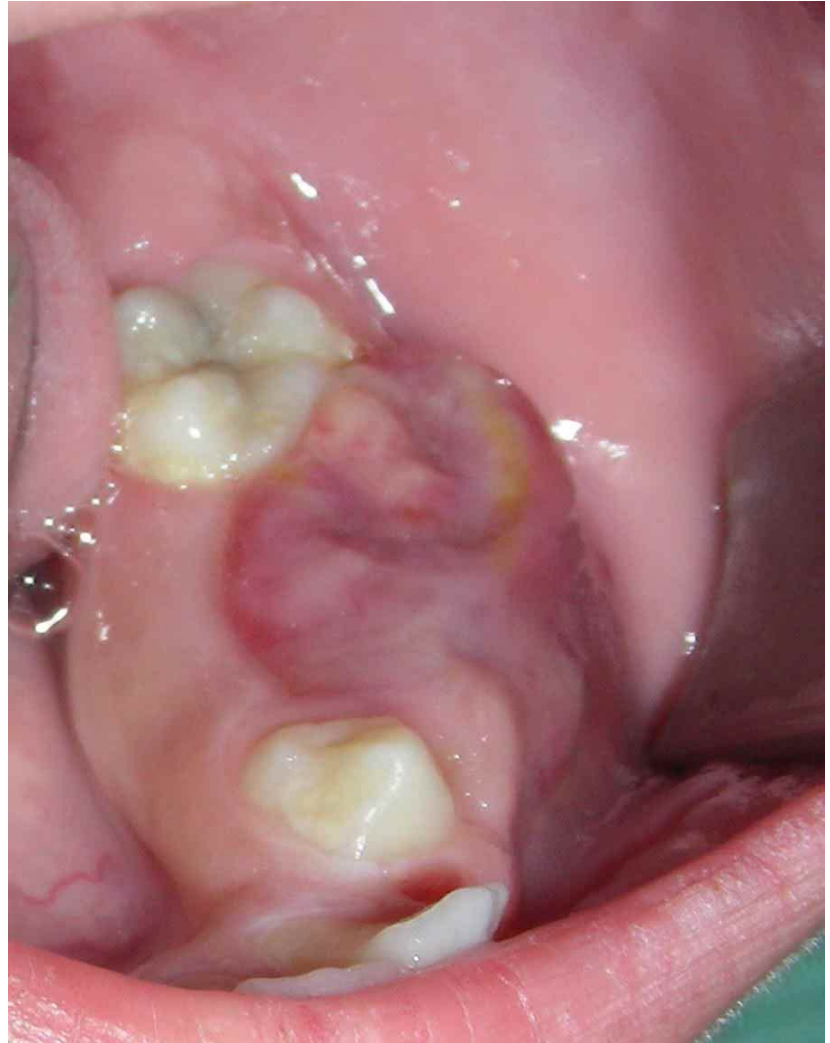

Fig. 1. Pre-operatory view of the lesion, showing buccal and lingual expansion, with antagonistic teeth print.

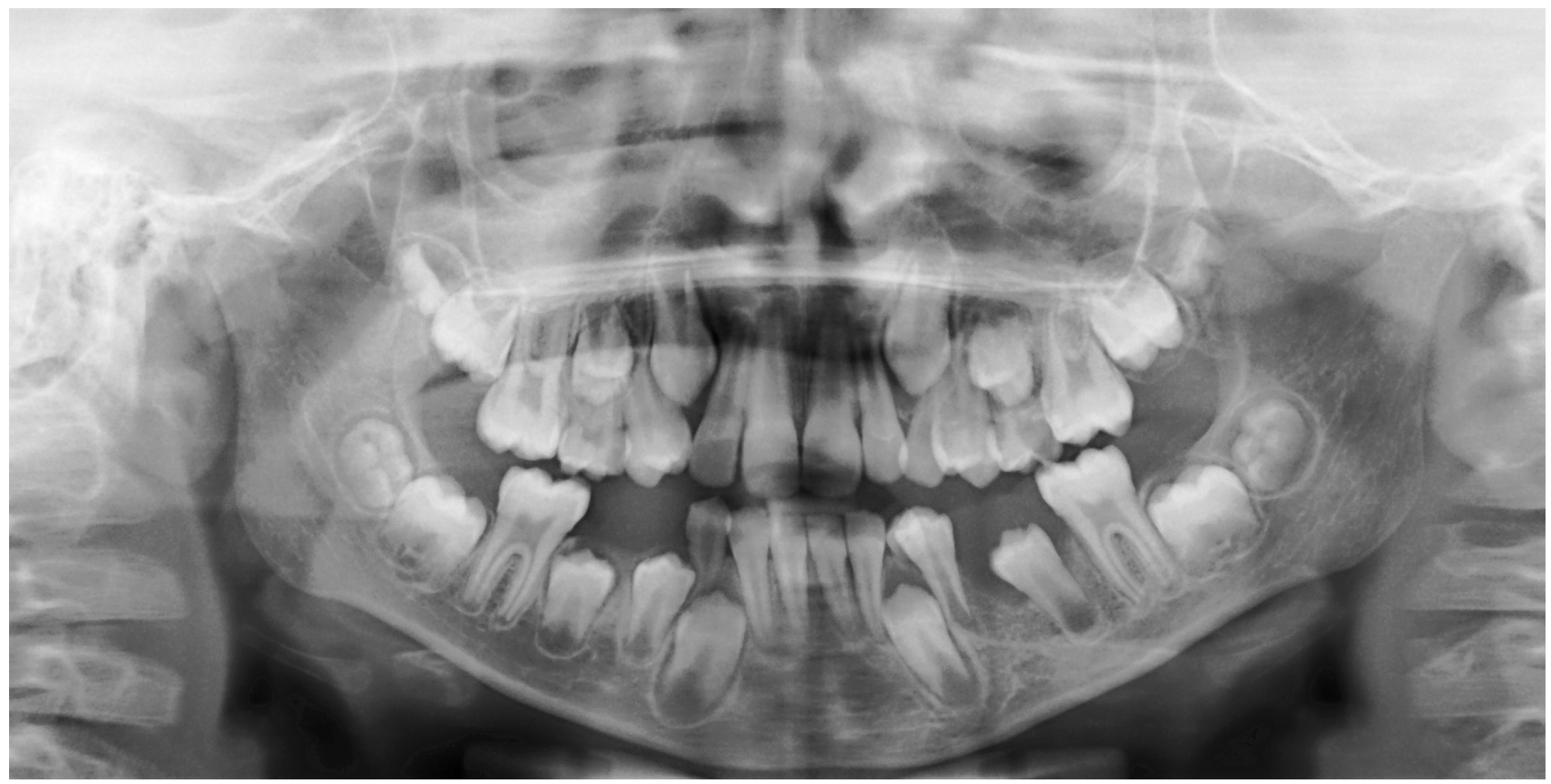

Fi. 2. Panoramic radiograph showing a well-defined radiolucency extending from the first permanent molar to the first premolar. 
An incisional biopsy under local anesthesia was performed, preceded by a puncture with a fine needle to avoid a hemorrhage in case of central hemangioma. The anatomo-pathological result of the biopsy suggested a central giant cell granuloma.

Considering results of the panoramic radiograph, the biological assessment and the biopsy, a surgical intervention (curettage of the lesion) was decided and intraorally performed under local anesthesia. A complete curettage of all colonized woven bone trabeculae of "wet sugar" consistency was performed until bone tissueof healthy appearance was obtained. The patient tolerated the procedure well. The postoperative course was uncomplicated.

Six months postoperatively, the patient described no more discomfort and the clinical examination did not reveal any residual swelling or dental pain. Two year later no recurrence was noted (Fig. 3). A control panoramic radiograph shows a bone

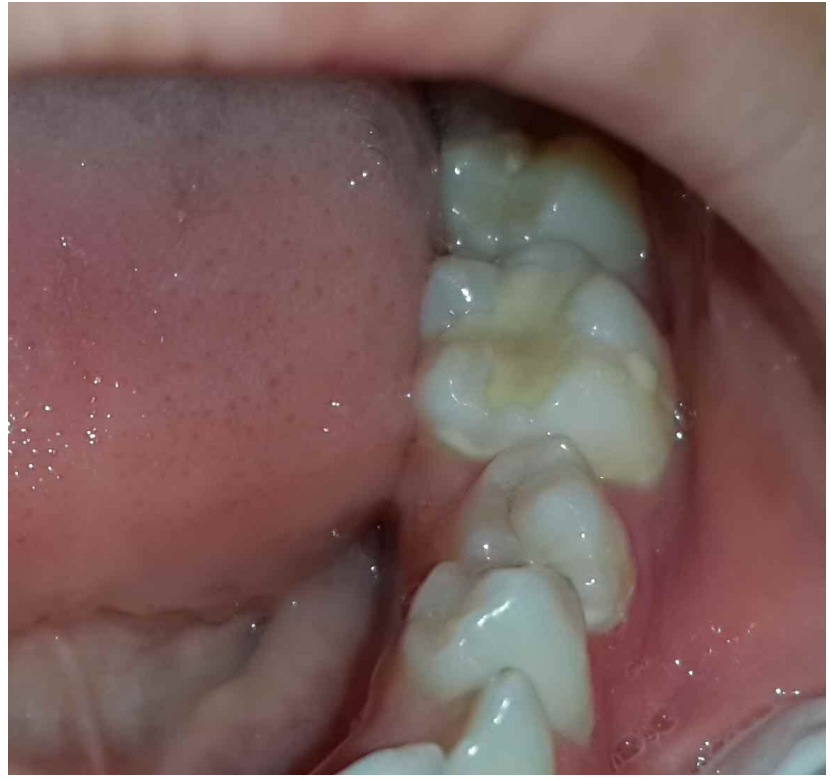

Fig. 3. Two year later (Follow-up). remodeling in the area of lesion (Fig. 4).

The excised biopsy was subjected to an anatomo-pathological examination. Histological examination showed a dense proliferation of spindleshaped cells with aggregations of multinucleated giant cells. Neither cellular atypia nor mitosis was noted.

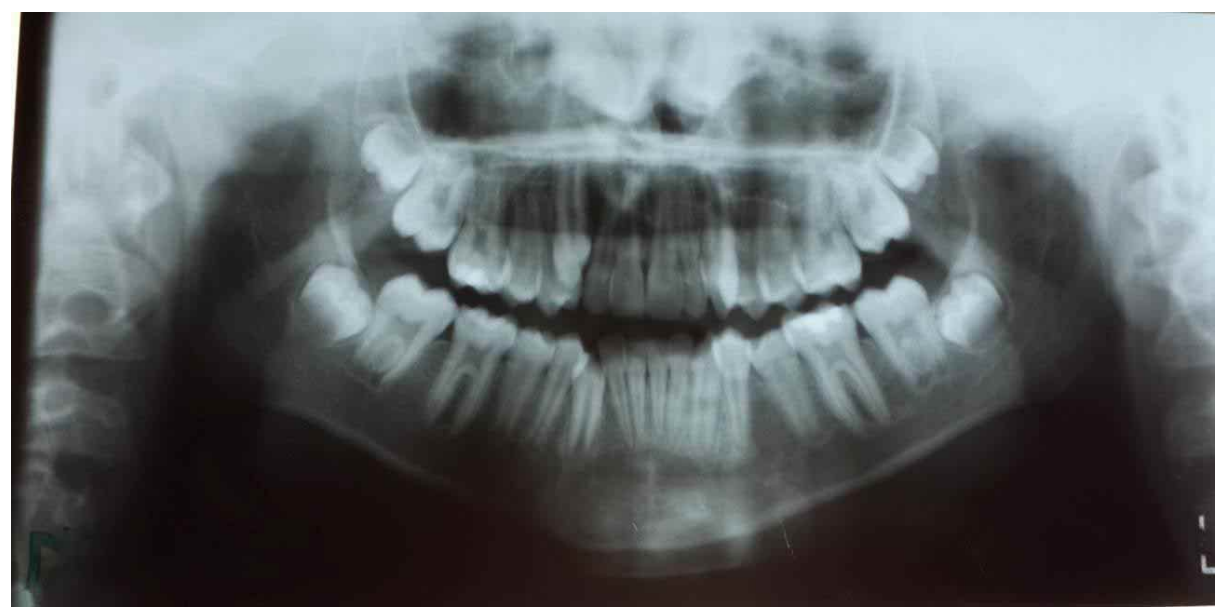

Fig. 4.Control panoramic radiograph showing bone remodeling in the area of lesion.

\section{DISCUSSION}

Central Giant Cell granuloma is a benign tumor of unknown etiology, belonging to a group of giant cell tumors and tumors-like which is still poorly defined (Auclair et al.).
It can occur at any age but presents most frequently in the 2nd and 3rd decades and involves the mandible more than the maxilla. It is twice as frequent in females (Liu et al.; Marx \& Stern, 2003). 
The clinical behavior of CGCG is variable. It ranges from slow-growing, asymptomatic swelling to an aggressive lesion which manifests with pain. It may be discovered accidentally during routine radiographic examination or in presence of signs of facial asymmetry, loosening or displacement of teeth and difficulty in mastication. Palpation reveals a rubbery, elastic sensation where the bone is thin. The lesions develop without paresthesia. Associated tooth may become mobile but remain vital (Liu et al.; O' Regan et al., 2001).

The radiological appearance of CGCG is variable. Usually the lesion appears as a unilocular or multilocular radiolucency. It may be well-defined or illdefined with variable expansion and destruction of the cortical plate 8,9 . In our case we noted a well-defined radiolucency.

Depending on clinical and radiographic features, central giant cell granuloma can be classified into two types: The first type is non-aggressive, slow growing, does not show root resorption or cortical perforation, and often shows new bone formation. The second type is aggressive, grows quickly, shows pain, cortical and root resorption, displaces anatomical structures such as teeth, the mandibular canal and the floor of maxillary antrum with a high recurrence rate (O' Regan et al.; Marx \& Stern; Sholapurkar et al., 2008; Rajendran et al., 2009). The present case is in favor of nonaggressive lesion.

The distinctive feature of this lesion is the difficulty of diagnosis. Clinical and radiological features are not specific. The final diagnosis rests on histopathology.

Histological examination shows the presence of multinuclear giant cells, surrounded by mesenchymal ovoid and fusiform cells, with locations of blood extravasation, associated with pigmentation caused by the phagocytic hemosiderin and reactive bone formation (Liu et al.,; Sholapurkar et al.).

Numerous giant cell rich lesions of jaws could be considered in the differential diagnosis. These include giant cell tumor, cherubism, aneurysmal bone cyst and jaw tumor of hyperparathyroidism (Venkateshwarlu et al., 2010).

However, aneurysmal bone cyst shows bloodfilled cystic cavities. Cherubism is an autosomal dominant genetic disorder with bilateral involvement. Hyperparathyroidism brown tumor is characterized by multiple locations, which is different of our case. The tumor is associated with high serum levels of parathyroid hormone, serum calcium, phosphorous and alkaline phosphate. A phosphocalcic assessment was shown to be totally normal in our patient (Bataineh et al.; Liu et al.; Venkateshwarlu et al., 2010).

The main difficulty is to differentiate CGCG from giant cell tumor (GCT) which presents a risk of malignant transformation (Bataineh et al.). It is similar to CGCG especially the aggressive type. However, GCT is 10 times less frequent, and affects older patients, which does not correspond to the age of our clinical case. Histologically, giant cells are larger and more-rounded, uniformly dispersed and have a greater number of nuclei. Several authors conclude that GCT and CGCG are on a spectrum of a single disease process, by reporting some histopathological pictures of 'aggressive' CGCGs which were totally indistinguishable from GCT 12. This led these scientists to believe that CGCGs and GCTs of the extragnathic are not distinct entities but rather represent a continuum of the same disease process modified by the age of the patient, site of occurrence, and possibly other factors that are as yet not clearly understood (Bataineh et al.; Whitaker \& Waldron, 1993).

The management of CGCG depends on the clinical and radiographic findings. Surgery is still the most frequently applied treatment; however, several alternative treatments have been suggested. The choice depends on the lesion's behavior (aggressive versus non aggressive), the location, size, and radiographic appearance of the lesions. The surgical procedures range from radical (en bloc resection) to more conservative approaches (curettage) (Mooney et al.).

Other alternatives have been described in the literature, to avoid the need for mutilating surgery in children. They consist on administration of systemic calcitonin which inhibits osteoelastic activity. Intralesional injections of corticosteroids appear useful in the management of aggressive CGCG and subcutaneous a- interferon injections with antiangiogenic effects. Bisphosphonates have been also administered intravenously in CGCG with promising results (Bataineh et al.; Sholapurkar et al., 2008).

Recurrence rates ranging from $11 \%$ to $49 \%$ have been reported. Higher incidence of recurrence $(72 \%)$ is found in aggressive lesions and in younger patients, especially in young male patients (Mooney et al.). These recurrences are related to incomplete 
removal of a friable, bleeding lesion, which is more difficult to remove between teeth, or to a greater possibility of incomplete excision in a larger-sized lesion. There is a small difference in recurrence rate between the maxilla and the mandible $(28.6 \%$ and $23.2 \%$, respectively). A possible explanation for this difference may be that surgical curettage in the maxilla is more difficult (Rajendran et al.).

Two other treatment concepts have been advanced to reduce the recurrence of this lesion. One is the use of Carnoy's solution as a cellular fixative; another is to perform endodontic therapy of erupted teeth within the lesion. However, these solutions do not show a reduction in recurrences (Bataineh et al.).

The present case was treated with curettage; the patient shows no signs of recurrence. The first premolar has normally erupted. No particular image was seen on panoramic radiography after two years of following up.

Some authors underlined the importance of a combined management of children with CGCG by the cooperation of the maxillofacial and pediatric dentistry teams, in initial diagnosis and in subsequent treatment of co-existing dental disease, in order to create a more preventive program and prevision of prosthetic replacement of teeth.

Central Giant Cell Granuloma is a less frequent pathology in daily dental practice. The clinical behavior of this lesion is quite variable and difficult to predict. Hence the need of rigorous diagnosis approach based on meticulous history taking, careful clinical and radiological examinations, targeted biological assessment and anatomopathological analysis.

Early diagnosis mainly in children may allow early treatment and avoid harm to the permanent teeth.

BAHBAH, S.; DGHOUGHI, S.; CHHOUL, H.; EL WADY, W. Granuloma Central de células gigantes en un niño - Reporte de un caso. Int. J. Odontostomat., 10(3):393-397, 2016.

RESUMEN: En este artículo se describe un caso de granuloma central de células gigantes en la región posterior derecha de la mandíbula en un niño de 10 años de edad. La lesión se retiró por legrado y se realizó un examen histopatológico.

PALABRAS-CLAVE: granuloma central de células gigantes, niño, mandíbula.

\section{REFERENCES}

Auclair, P. L.; Cuenin, P.; Kratochvil, F. J.; Slater, L. J. \& Ellis, G. L. A clinical and histomorphologic comparison of the central giant cell granuloma and the giant cell tumor. Oral Surg. Oral Med. Oral Pathol., 66(2):197-208, 1988.

Bataineh, A. B.; Al-Khateeb, T. \& Rawashdeh, M. A. The surgical treatment of central giant cell granuloma of the mandible. $J$. Oral Maxillofac. Surg., 60(7):756-61, 2002.

De Lange, J. \& Van den Akker, H. P. Clinical and radiological features of central giant-cell lesions of the jaw. Oral Surg. Oral Med. Oral Pathol. Oral Radiol. Endod., 99(4):464-70, 2005.

Kaffe, I.; Ardekian, L.; Taicher, S.; Littner, M. M. \& Buchner, A. Radiologic features of central giant cell granuloma of the jaws. Oral Surg. Oral Med. Oral Pathol. Oral Radiol. Endod., 81(6):7206, 1996.

Marx, R. E. \& Stern, D. Oral and Maxillofacial Pathology: A Rationale for Diagnosis and Treatment. 2nd ed. Hanover Park, Quintessence, 2003. pp.836-41.

Liu, B.; Yu, S. F. \& Li, T. J. Multinucleated giant cells in various forms of giant cell containing lesions of the jaws express features of osteoclasts. J. Oral Pathol. Med., 32(6):367-75, 2003.

Mooney, G. C.; McMahon, J.; Ward, S .E.; Davidson, L .E. \& North, $S$. Management of central giant cell granuloma: discussion of two cases. Int. J. Paediatr. Dent., 17(2):139-44, 2007.

O' Regan, E. M.; Gibb, D. H. \& Odell, E.W. Rapid growth of giant cell granuloma in pregnancy treated with calcitonin. Oral Surg.Oral Med. Oral Pathol. Oral Radiol. Endod., 92(5):532-8, 2001.

Rajendran, R.; Sivapathasundharam, B. \& Shafer, H. L. Shafer's Textbook of Oral Pathology. 6th ed. New Delhi, Elsevier/Reed Elsevier, 2009.

Sholapurkar, A. A.; Pai, K. M. \& Ahsan, A. Central giant cell granuloma of the anterior maxilla. Indian J. Dent. Res., 19(1):78-82, 2008.

Venkateshwarlu, M.; Geetha, P. \& Radhika, B. Central giant cell granuloma: Aggressive lesion can cause jaw to swell, and loosen teeth. I. J. D. A., 2:134-7, 2010.

Whitaker, S. B. \& Waldron, C. A. Central giant cell lesions of the jaws. A clinical, radiologic, and histopathologic study. Oral Surg. Oral Med. Oral Pathol., 75(2):199-208, 1993.

Correspondence to:

Soukayna Bahbah

BP 6212, Madinat Al Irfan

Rabat

MOROCCO

Email: bahbah.soukayna@hotmail.fr

Received: 29-02-2016

Accepted: 14-11-2016 